in vivo $35: 2845-2853(2021)$

doi:10.21873/invivo.12572

\title{
IL27 T4730C Polymorphism and Serology in Multiple Sclerosis: A Pilot Study
}

\author{
IOANA S. BARAC ${ }^{1}$, VITALIE VĂCĂRAȘ ${ }^{1}$, ANGELA COZMA ${ }^{2}$, MĂDĂLINA VĂLEANU ${ }^{3}$, \\ NICOLETA DECEA ${ }^{4}$, DAFIN F. MUREȘANU ${ }^{1}$ and LUCIA M. PROCOPCIUC ${ }^{5}$ \\ ${ }^{1}$ Department of Clinical Neurosciences, Iuliu Hațieganu University of Medicine and Pharmacy Cluj-Napoca, \\ Cluj-Napoca, Romania; \\ ${ }^{2}$ Department of Internal Medicine, Iuliu Hațieganu University of Medicine and Pharmacy Cluj-Napoca, \\ Cluj-Napoca, Romania; \\ ${ }^{3}$ Department of Medical Informatics and Biostatistics, Iuliu Hațieganu University of Medicine and Pharmacy Cluj-Napoca, \\ Cluj-Napoca, Romania; \\ ${ }^{4}$ Department of Physiology, Iuliu Hațieganu University of Medicine and Pharmacy Cluj-Napoca, Cluj-Napoca, Romania; \\ ${ }^{5}$ Department of Medical Biochemistry, Iuliu Hațieganu University of Medicine and Pharmacy Cluj-Napoca, \\ Cluj-Napoca, Romania
}

\begin{abstract}
Background: Multiple sclerosis (MS) is one of the most debilitating neurological diseases of young adults. The presence of a single nucleotide polymorphism in the promoter regions of the interleukin 27 gene (IL27 T4730C, rs181206) may alter the transcription and the production of cytokine levels, leading to MS. Patients and Methods: We performed a case-control study including 82 individuals: 51 patients diagnosed with MS and 31 healthy controls. Polymerase chain reaction-restriction fragment length polymorphism was used in order to determine the genotypes for the IL27 T4730C polymorphism and enzyme-linked immunosorbent assay to measure the serum IL27 level. Results: Carriers of the T4730C polymorphism were found to have a 6-fold [95\% confidence intervaI $(C I)=1.83-19.63, p=0.002]$ increased risk for MS. Univariate logistic regression analysis showed an increased frequency of the TC4730 heterozygous genotype (39.2\% vs. 9.7\%) and also of the C4730 allele $(27.45 \%$ vs. $8.06)$ in patients compared to controls, with a 6.02-fold increased risk (95\% CI=1.61-22.46, $p=0.006)$ and a 4.31-fold increased risk (95\% CI=1.57-11.87, $p=0.002$ ) of developing MS. IL27 levels were significantly lower in patients compared
\end{abstract}

This article is freely accessible online.

Correspondence to: Vitalie Văcăraș, Department of Clinical Neurosciences, "Iuliu Hațieganu" University of Medicine and Pharmacology, Victor Babes Street Nr 43, Cluj-Napoca 400000, Romania. Tel: +40 0728730373, e-mail: vitalievacaras.umf@gmail.com

Key Words: IL27, IL27 T4730C, multiple sclerosis. to controls (12.35 versus $14.34 \mathrm{pg} / \mathrm{ml}, \mathrm{p}=0.039)$, without significant differences between genotypes. Multivariate logistic analysis showed that IL27 T4730C polymorphism (odds ratio=6.272, 95\% CI=1.84-21.40, $p=0.003)$ and smoking (odds ratio $=4.214,95 \% C I=1.39-12.74, p=0.011$ ) represented independent risk factors for MS. Conclusion: Our study provides a possible link between IL27 level and IL27 T4730C gene polymorphism and the risk for developing MS in a Romanian population.

Multiple sclerosis (MS) is a central nervous system autoimmune disease, characterized by chronic inflammation, myelin damage, oligodendrocyte death and axonal loss leading to neurodegeneration and neurological dysfunctions (1). The pathogenesis of MS is linked to the activation of Tlymphocytes, influenced by environmental and gene interactions (2). In MS, the genetic influence has been demonstrated by genome-wide association studies and familial studies, discovering more than 50 susceptibility loci that contribute to disease onset, such as the polymorphisms located on chromosome $6 \mathrm{p} 21$, expressing the human leukocyte antigen class II region of the major histocompatibility complex (MHC), and in other non-MHC loci located near or inside genes controlling the function of the adaptive immune system (3). The involvement of MHC polymorphisms in autoimmune diseases is still unclear but some studies suggested that the binding between T-cell recognition sites and the peptide cleft of MHC molecules might be one explanation, associated with a reduced population of T-regulatory cells and cross reactivity between infectious antigens and self-proteins (4-6). In this respect, 
previous studies suggested that genes encoding cytokines involved in the activation and survival of T-helper 17 (Th17) cells may also contribute to MS predisposition and susceptibility, enhancing the destruction of myelin or modulating its repair (7). Cytokines and their pleiotropic effects were studied for a better understanding of MS pathogenesis. Exploring the connection between cytokines and their genetic polymorphisms leads to the observation that a single nucleotide polymorphism (SNP) in the promoter region of a cytokine gene may influence the secretory function of immune cells (8).

Different studies evaluating autoimmune diseases, including MS, reported the implication of interleukin 27 (IL27) in immunopathogenesis. IL27 is a novel member of the IL12 family, known for both its pro- and antiinflammatory functions, with distinct roles in shaping the activity of T-cells. IL27 is a heterodimer composed of Epstein-Barr-induced gene 3 product (EBI3) and IL27p28 (9). IL27 regulates the immune response through its heterodimeric IL27Ra/GP130 receptor, activating multiple signaling cascades, including signal transducer and activator of transcription 1 (STAT1) and 3 (STAT3) (9). The expression of IL27 receptors on the surface of distinct cells, such as uterine natural killer (NK) cells, placental trophoblasts, microglia, endothelial cells and plasma cells, reinforces the important role of IL27 in maintaining a wellbalanced immune status in fragile immune environments such as the brain and uterus (10). The activity of T-cells is directly influenced by IL27 $(11,12)$. In chronic inflammation through immune down-modulation, IL27 is essential in preventing tissue injuries and organ dysfunction (11). Elevated levels of IL27 were found in the synovial fluids of patients with rheumatoid arthritis (RA), in the colonic mucosa of patients with Crohn's disease, in the serum of patients with psoriasis, and in patients with MS following treatment with interferon (11). In the brain, IL27 produced by astrocytes and microglial cells is recognized for its neuroprotective effects, enhancing the production of nerve growth factor and neurotrophic factor, promoting remyelination $(12,13)$. Postmortem studies revealed elevated levels of IL27 in demyelinating plaques of patients with MS compared to normal control brain tissues (14).

One of the polymorphisms associated with the IL27p28 gene, T4730C (rs181206), has been investigated in esophageal, hepatocellular and colorectal neoplasms and other autoimmune disorders: immune thrombocytopenia, systemic lupus erythematosus (SLE), RA, Behcet's disease and ulcerative colitis $(15,16)$. T4730C (rs181206) is a polymorphism located in exon 4 of the IL27 gene, consisting of a single nucleotide substitution of $\mathrm{T}$ with $\mathrm{C}$ at nucleotide 4730 , which determines the substitution of Leu with Pro in 119 position of IL27 (Leu119Pro) (17-19). This polymorphism was shown to generate binding sites for transcriptional factors such as splicing factor 2/alternative splicing factor 2 (SF2/ASF2) controlling alternative splicing $(20,21)$.

Aim of the study. We investigated the influence of T4730C (rs181206) polymorphism and serum IL27 levels on susceptibility to MS. A second objective was to establish the existence of a relationship between the genetic polymorphism and serum IL27 levels in patients MS and controls in order to reveal a possible new biomarker for disease diagnosis and prognosis.

\section{Patients and Methods}

Patients and controls. Fifty-one patients with MS, 30 (58.5\%) females and $21(41.17 \%)$ males (mean age $=34.71 \pm 10.31$ years), and 31 controls without a personal or familial history of MS, $20(64.5 \%)$ females and $11(35.48 \%)$ males (mean age $=35.13 \pm 11.21$ years) were included in our study between March 2019 and January 2020. The patients were recruited from the National Program of MS of the Neurology Clinic, Cluj-Napoca, Romania. The MS diagnosis was based on clinical and radiological findings, according to the 2017 Mc Donald criteria (22). The information was obtained from neurological examinations and personal interviews. Data about radiological investigations were obtained from patients' files.

The inclusion criteria were: Diagnosis of MS, at the beginning of the disease, without previous treatment for MS. The exclusion criteria were: Other autoimmune diseases such as SLE, RA, ankylosing spondylitis, inflammatory bowel diseases, psoriasis, type 1 diabetes mellitus; clinical relapse at the time of evaluation, use of cortisone in the previous month, recent use of other immunomodulatory therapies.

Both groups shared a common geographical area, and had the same ethnicity and socioeconomic status.

Ethics statement. The study was performed in conformity with the principles of the Declaration of Helsinki. The study was approved by the Research Ethics Committee of the Iuliu Haţieganu University of Medicine and Pharmacy, Cluj-Napoca, Romania (Protocol Code 31, 25.02.20219). All patients were informed about the aim of the study and signed an informed consent form.

Sampling and DNA extraction. Before initiating any immunomodulatory treatment, $10 \mathrm{ml}$ of peripheral blood were collected through venipuncture in EDTA anticoagulated tubes for both patients with MS and controls. High molecular weight DNA was isolated using a Zymoresearch kit (Quick-DNAMiniprep, Kit-Zymo Research Corporation, Freiburg, Germany). The probes were stored at $-20^{\circ} \mathrm{C}$ until polymerase chain reaction (PCR) analysis was carried out.

PCR-restriction fragment length polymorphism analysis for IL27T4730C polymorphism. The IL27-T4730C polymorphism was identified using the method described by Anaraki Mohammad et al. (16).

Twenty nanograms of genomic DNA were amplified in $25 \mu \mathrm{l}$ mixture containing $200 \mu \mathrm{M}$ dNTPs (dATP, dGTP, dCTP, dTTP), 2.0 $\mathrm{mM} \mathrm{MgCl} 2,0.2 \mu \mathrm{M}$ primers (forward primer and reverse primer; Kaneka Eurogentec S.A. Biologics Division, Liege, Belgium), 0.65 U Taq DNA polymerase [Taq buffer, $20 \mathrm{mM}$ Tris- $\mathrm{HCl}$ (pH 8.0), 1 


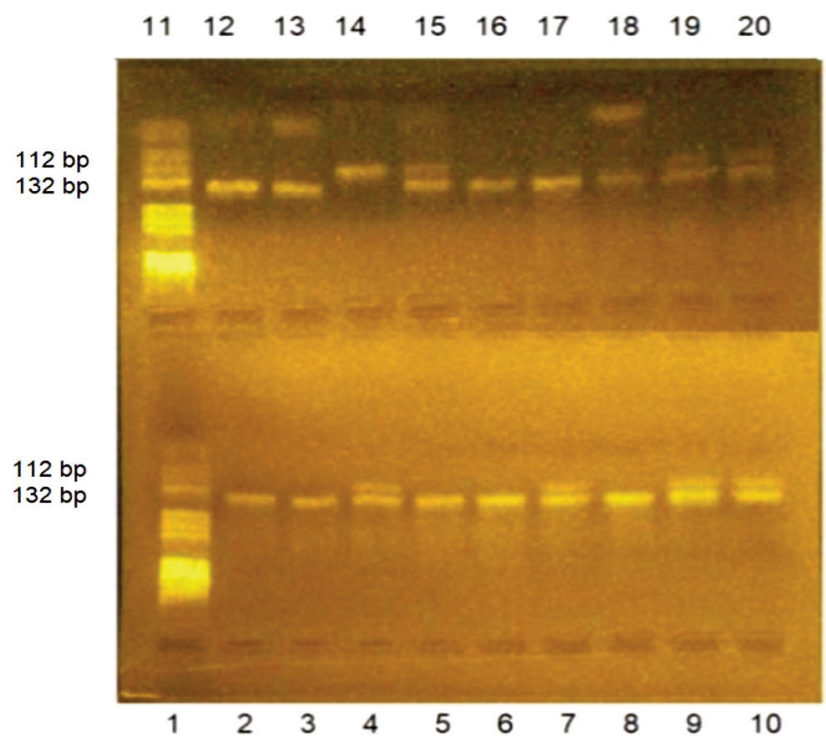

Figure 1. Agarose gel electrophoresis for identification of interleukin 27 (IL27) T4730C genotype. Lanes 1/11: pBRHaeIII digest DNA molecular marker; lanes 2/12: polymerase chain reaction-amplified fragment; lanes 3, 5, 6, 8/13, 16, 17, 18: homozygous TT4730 genotype; lanes 4, 7, 9, 10/15, 19, 20: heterozygous TC4730 genotype; lane 14: homozygous CC4730 genotype.

$\mathrm{mM}$ dithiothreitol, $0.1 \mathrm{mM}$ EDTA, $100 \mathrm{mM} \mathrm{KCl,} 0.5 \%$ (v/v) Nonidet P40, 0.5\% (v/v) Tween20 and 50\% (v/v) glycerol].

Fast PCR amplification was performed in an iCycler C1000 BioRad (Bio-Rad Life Science, Hercules, CA, USA) under the following conditions: Initial denaturation at $95^{\circ} \mathrm{C}$ for $0.6 \mathrm{~s}$, followed by 34 cycles of denaturation at $95^{\circ} \mathrm{C}$ for $0.3 \mathrm{~s}$, annealing of the primers at $67^{\circ} \mathrm{C}$ for $0.3 \mathrm{~s}$, and a final extension at $72^{\circ} \mathrm{C}$ for $0.3 \mathrm{~s}$. The specificity of the amplification reaction was checked by electrophoresis of $10 \mu \mathrm{l} \mathrm{PCR}$ product on $2 \%$ agarose gel stained with $10 \mathrm{mg} / \mathrm{ml}$ ethidium bromide solution. The gel was visualized on a UV transilluminator. The size of the PCR fragment was $132 \mathrm{bp}$.

The PCR product was incubated for $3 \mathrm{~h}$ with $5 \mathrm{U}$ of Fual restriction endonuclease [New England Biolabs (UK), Ltd, Hitchin, UK] in $10 \mu \mathrm{l}$. The wild-type $T 4730$ allele was characterized by the presence of a 132 bp fragment, while the mutated $C 4730$ allele was characterized by the presence of $112 \mathrm{bp}$ and $20 \mathrm{bp}$ fragments.

The three genotypes were identified by agarose gel electrophoresis and analyzed on a UV illuminator after staining with $10 \mathrm{mg} / \mathrm{ml}$ ethidium bromide solution. The homozygous TT4730 genotypes were identified by the presence of one fragment of 132 bp. The homozygous CC4730 genotypes were identified by the presence of two fragments of $20 \mathrm{bp}$ and $112 \mathrm{bp}$, while the heterozygous TC4730 genotype involved the presence of three fragments of $20 \mathrm{bp}, 112 \mathrm{bp}$ and $132 \mathrm{bp}$ (Figure 1).

Serum IL27 determination. IL27 concentrations were determined in human serum, using micro enzyme-linked immunosorbent assay (ELISA) plates pre-coated with an antibody specific to human IL27 (Elabscience Biotechnology Inc., Houston, TX, USA) according to the manufacturer's protocol.
For each probe, $100 \mu$ l biotinylated detection antibody-specific substrate reagent was used. The reaction was stopped using $50 \mu \mathrm{l}$ stop solution. The optical density at $450 \mathrm{~nm}$ was then measured spectrophotometrically using a microplate reader (Absorbance Microplate Reader Sunrise Tecan; Tecan Group Ltd., Männedorf, Switzerland) and Biochrom Asys Atlantis Microplate Washer (Biochrom Ltd. Cambridge, UK). The serum IL27 level was measured using standard curves in which the optical density was proportional to the concentration of human IL27 (sensitivity=18.75 pg/ml).

Statistical analysis. Statistical analysis was performed using SPSS software, version 25.0 (IBM, Armonk, NY, USA). The normality of the distribution of quantitative data was verified with the ShapiroWilk or Kolmogorov-Smirnov test. The significance level was $\alpha=0.05$. The mean \pm standard deviation was used to describe quantitative data with normal distribution and the median and interquartile range (IQR) for data that did not. Qualitative data were expressed numerically and as percentages. According to the data distribution, Student's $t$-test or nonparametric Mann-Whitney test was used to compare the means of two independent groups. Fisher's exact probability test or the chi-square test was used to evaluate differences in genotypic and allelic frequencies between the examined groups. The strength of the association between categorical variables was expressed as odds ratios (OR) with $95 \%$ confidence intervals (95\% CI). The association between IL27 gene polymorphisms and MS risk was estimated by computing ORs and 95\% CIs from a multivariate logistic regression analysis.

We analyzed the sample size using the Gpower program (23) which indicated that for a total of 40 random participants in the patient group and 20 random participants in the control group, a medium-size effect (0.5) with $\alpha=0.05$ and a power of 0.8 was calculated. In order to have a statistically significant power, we used a greater number of participants in both groups. Therefore, the statistical power for all of the studied variants was greater than $80 \%$ in the validation population.

\section{Results}

In the present study, we did not find any significant difference regarding age $(p=0.97)$ and gender $(p=0.61)$ between the two groups. Patients with MS were significantly more likely to be smokers (49\% versus $19.4 \%, p=0.007$ ) and tended to be alcohol drinkers ( $31.4 \%$ versus $12.9 \%, p=0.067$ ) compared to controls. Patients in the control group were also mainly from an urban environment $(p=0.003)$. The clinical and demographic features of the studied patients and controls are summarized in Table I.

Association between IL27-T4730C gene polymorphism, IL27 level and MS. The distribution of genotypes in patients with MS and controls showed significant differences for those with homozygous (CC4730) and heterozygous (TC4730) genotypes $(p=0.006)$, as well as for carriers of the $C$ allele in patients with MS compared to controls $(p=0.047)$. In the control group, the majority of controls (87\%) presented a homozygous TT4730 genotype and $91.93 \%$ were carriers of the $\mathrm{T}$ allele (Table II). 
in vivo $35: 2845-2853(2021)$

Table I. Demographics and clinical parameters of patients with multiple sclerosis (MS) and healthy controls.

\begin{tabular}{|c|c|c|c|c|c|}
\hline Variable & & MS $(\mathrm{N}=51)$ & Healthy controls $(\mathrm{N}=31)$ & OR $(95 \% \mathrm{CI})$ & $p$-Value* \\
\hline \multirow{2}{*}{ Age, years } & Mean \pm SD & $34.71 \pm 10.31$ & $35.13 \pm 11.21$ & & 0.97 \\
\hline & Median (IQR) & $32(27-42)$ & $28(25-48)$ & & \\
\hline Age at onset, years & Median (IQR) & $29(24-38)$ & & & \\
\hline \multirow[t]{2}{*}{ Place of residence, $\mathrm{n}(\%)$} & Urban & $39(76.5)$ & $31(100)$ & & 0.003 \\
\hline & Rural & $12(23.53)$ & & & \\
\hline \multirow[t]{2}{*}{ Gender, n (\%) } & Female & $30(58.8)$ & $20(64.5)$ & Reference & 0.61 \\
\hline & Male & $21(41.17)$ & $11(35.48)$ & $1.164(0.51-3.20)$ & \\
\hline \multirow[t]{2}{*}{ Smoking, n (\%) } & No & $26(50.98)$ & $25(80.64)$ & Reference & 0.007 \\
\hline & Yes & $25(49)$ & $6(19.4)$ & $4.01(1.41-14.1)$ & \\
\hline \multirow{2}{*}{ Alcohol use, n (\%) } & No & $35(68.62)$ & $27(87.09)$ & Reference & 0.067 \\
\hline & Yes & $16(31.4)$ & $4(12.9)$ & $3.09(0.92-10.29)$ & \\
\hline \multirow[t]{3}{*}{ MS, n (\%) } & CIS & $18(35.3)$ & & & \\
\hline & $\mathrm{RR}$ & $30(58.8)$ & & & \\
\hline & SP & $3(5.9)$ & & & \\
\hline \multirow[t]{2}{*}{ Oligoclonal bands, n (\%) } & No & $25(49)$ & & & \\
\hline & Yes & $26(51)$ & & & \\
\hline
\end{tabular}

CI: Confidence intervaI; CIS: clinically isolated syndrome; IQR: interquartile range; OR: odds ratio; RR: relapsing/remitting; SD: standard deviation; SP: secondary progressive. *Student's $t$-test, Mann-Whitney-Wilcoxon test, chi-square test or Fisher's exact test.

Table II. Distribution of interleukin 27 (IL27)-T4730C polymorphism in patients with multiple sclerosis (MS) and healthy controls.

\begin{tabular}{lccc}
\hline & $\begin{array}{c}\text { MS } \\
(\mathrm{N}=51)\end{array}$ & $\begin{array}{c}\text { Healthy controls } \\
(\mathrm{N}=31)\end{array}$ & $p$-Value* \\
\hline $\begin{array}{l}\text { IL27 genotype, n (\%) } \\
\text { TT4730 }\end{array}$ & $27(52.9)$ & $27(87.1)$ & 0.006 \\
TC4730 & $20(39.2)$ & $3(9.7)$ & \\
CC4730 & $4(7.8)$ & $1(3.2)$ & \\
Allele, $\mathrm{n}(\%)$ & $74(72.54)$ & $57(91.93)$ & 0.047 \\
T4730 & $28(27.45)$ & $5(8.06)$ & \\
C4730 & & \\
\hline
\end{tabular}

*Fisher's exact test.

The median serum IL27 level was significantly lower for patients with $\mathrm{MS}$ at $12.35 \mathrm{pg} / \mathrm{ml}(\mathrm{IQR}=7.6-16.3 \mathrm{pg} / \mathrm{ml})$ compared to $14.34 \mathrm{pg} / \mathrm{ml}(\mathrm{IQR}=11.34-87.06 \mathrm{pg} / \mathrm{ml})$ for controls $(p=0.039)$ (Figure 2$)$.

The results of univariate logistic regression analysis showed that the TC4730 genotype, and having a $\mathrm{C}$ allele-bearing genotype were associated with susceptibility to MS (TC4730 versus TT4730: unadjusted $\mathrm{OR}=6.02$, 95\% $\mathrm{CI}=1.61-22.46$, $p=0.002)$; (TC4730+CC4730 versus TT4730: unadjusted $\mathrm{OR}=6,95 \% \mathrm{CI}=1.83-19.63, p=0.002)$. We also observed a significant association between carrying a $C 4730$ allele and the risk for $\mathrm{MS}$ (unadjusted $\mathrm{OR}=4.31,95 \% \mathrm{CI}=1.57-11.87$, $p=0.002$ ). The risk of developing MS increased in the case of smoking patients compared to non-smokers (unadjusted $\mathrm{OR}=4.01,95 \% \mathrm{CI}=1.41-11.41, p=0.009)$. In addition, there was a tendency for an increased risk for MS development in association with alcohol intake (unadjusted OR=3.09, 95\% $\mathrm{CI}=0.92-10.3, p=0.067)$. The results of univariate logistic regression analysis are shown in Table III.

Furthermore, multivariate logistic regression showed that the risk of developing $\mathrm{MS}$ was 6.272-fold (95\% CI=1.84$21.40, p=0.003$ ) increased in carriers of the IL27-T4730C polymorphism and 4.214 -fold $(95 \% \mathrm{CI}=1.39-12.74, p=0.011)$ increased in smoking patients. The results of multivariate logistic regression analysis are shown in Table IV.

In the analysis of serum IL27 according to genotype, the median serum IL27 levels were 12.11 (IQR=8.17-15.91 pg/ml) and 13.55 (IQR=8.43-37.68 pg/ml) in carriers of the TC4730, CC4730 genotypes, and 12.75 (IQR=7.07-17.7 $\mathrm{pg} / \mathrm{ml})$ in carriers of the TT4730 genotype ( $p>0.05)$ (Figure 3$)$.

\section{Discussion}

MS has a complex and variable evolution, strongly related to the immunopathogenic mechanism. Cytokines play a major role in the setting of autoimmune diseases, contributing to the initial self-tolerance breakdown, ultimately leading to a complex pathogenic autoimmune response (24).

IL27 has been extensively studied for its role in the regulation of IL17, a cytokine with a central role in autoimmune inflammation (24). The broad immunoregulatory roles of IL27 maintain an immunotolerogenic state in order to prevent autoimmunity (25).

A series of studies evaluating serum IL27 levels in patients with MS conducted by Babaloo et al. (26), Tang et al. (27) and Hasheminia et al. (28), showed lower levels in patients with newly diagnosed or progressive MS compared to a 


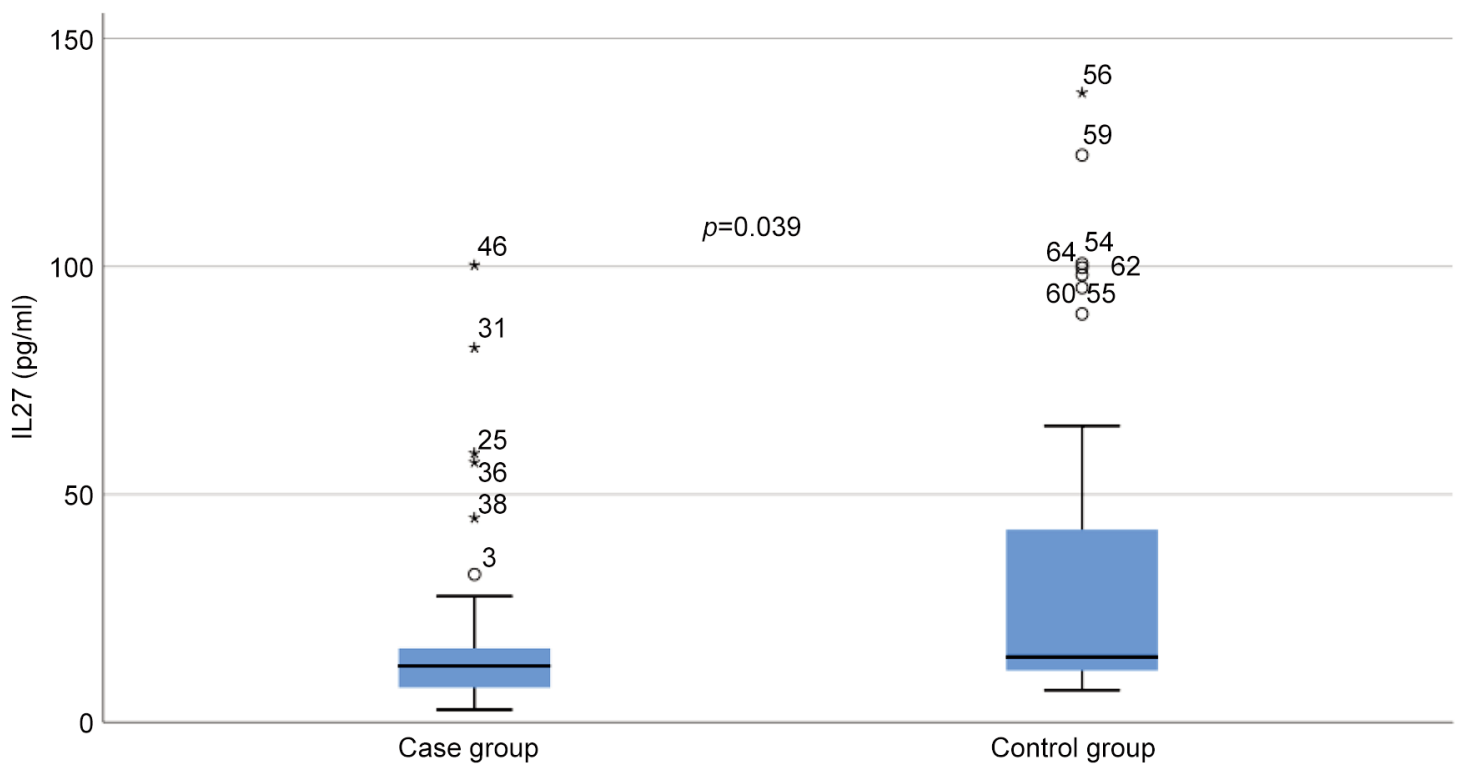

Figure 2. Serum interleukin 27 (IL27) levels in patients with multiple sclerosis (case group) and the control group. The box defines the interquartile range (IQR), i.e.the distance between the third and the first quartile. The line inside the box is the median and the whiskers are the upper and lower limits bound by $1.5 \times I Q R$.

Table III. Distribution of interleukin 27 (IL27)-T4730C polymorphism in patients with multiple sclerosis (MS) and healthy controls.

\begin{tabular}{lccc}
\hline Variable & Crude OR & $95 \%$ CI & $p$-Value* \\
\hline $\begin{array}{l}\text { Gender } \\
\quad \text { Males vs. females }\end{array}$ & 1.27 & $0.51-3.20$ & 0.609 \\
$\begin{array}{l}\text { Smoking } \\
\quad \text { Yes vs. no }\end{array}$ & 4.01 & $1.41-11.41$ & 0.009 \\
Alcohol & & & \\
$\quad$ Yes vs. no & 3.09 & $0.92-10.3$ & 0.067 \\
IL27-T4730C & & & \\
$\quad$ TC4730 vs. TT4730 & 6.02 & $1.61-22.46$ & 0.002 \\
CC4730 vs. TT4730 & 4 & $0.42-38.15$ & 0.356 \\
$\quad$ C-carrying vs. TT4730 & 6 & $1.83-19.63$ & 0.002 \\
$\quad$ T vs. C & 4.31 & $1.57-11.87$ & 0.002 \\
IL27 level (pg/ml) & 1.02 & $1.0-1.04$ & 0.017 \\
\hline
\end{tabular}

CI: Confidence intervaI; OR: odds ratio. *Crude Wald's test value.

control group. The serum IL27 levels were negatively correlated with the percentage of circulating Th17 cells, which highlights the influence of IL27 in the MS inflammatory process $(26,27)$. The aforementioned results are complementary to the findings of Naderi et al. (29), which showed a higher level of IL27 in patients under interferon- $\beta$ treatment for MS, and of Christensen et al. (30), which showed an elevated IL27 level in patients in MS remission. Moreover, other studies that investigated the serum levels of IL27 in autoimmune diseases revealed lower IL27
Table IV. Multivariate logistic regression analysis of risk factors associated with multiple sclerosis.

\begin{tabular}{lccccc}
\hline Variable & $\mathrm{b}$ & $\mathrm{SE}$ & $\mathrm{aOR}$ & $95 \% \mathrm{CI}$ & $p$-Value \\
\hline Smoking & & & & & \\
$\quad$ Yes $v s$. no & 1.438 & 0.565 & 4.214 & $1.39-12.74$ & 0.011 \\
$\quad$ IL27-T4730C & & & & & \\
$\quad$ C-carrying vs. TT & 1.836 & 0.626 & 6.272 & $1.84-21.40$ & 0.003 \\
$\quad$ Constant & -2.785 & 0.713 & 0.062 & & 0.000 \\
\end{tabular}

aOR: Adjusted odds ratio; b: estimated unstandardized regression coefficient; CI: confidence intervaI; IL27: interleukin 27 gene; SE: standard error. Wald's test adjusted $p$-value.

levels in patients with SLE compared to controls (31, 32). All the studies mentioned above share a common feature: the serum levels of IL27 were lower in patients compared to healthy controls, suggesting a role of IL27 in pathogenesis.

In our study, we confirmed these results, showing that the serum IL27 level was significantly lower in patients with MS than in controls.

Considering that cytokine gene polymorphisms influence the production of cytokines and their pleiotropic effects on the immune system cells, we also analyzed the T4730C polymorphism located in the IL27p28 gene and its role on serum IL27 levels in patients with MS and controls.

Paradowska-Gorycka et al. suggested that a lower serum expression of IL27 may be a consequence of the 


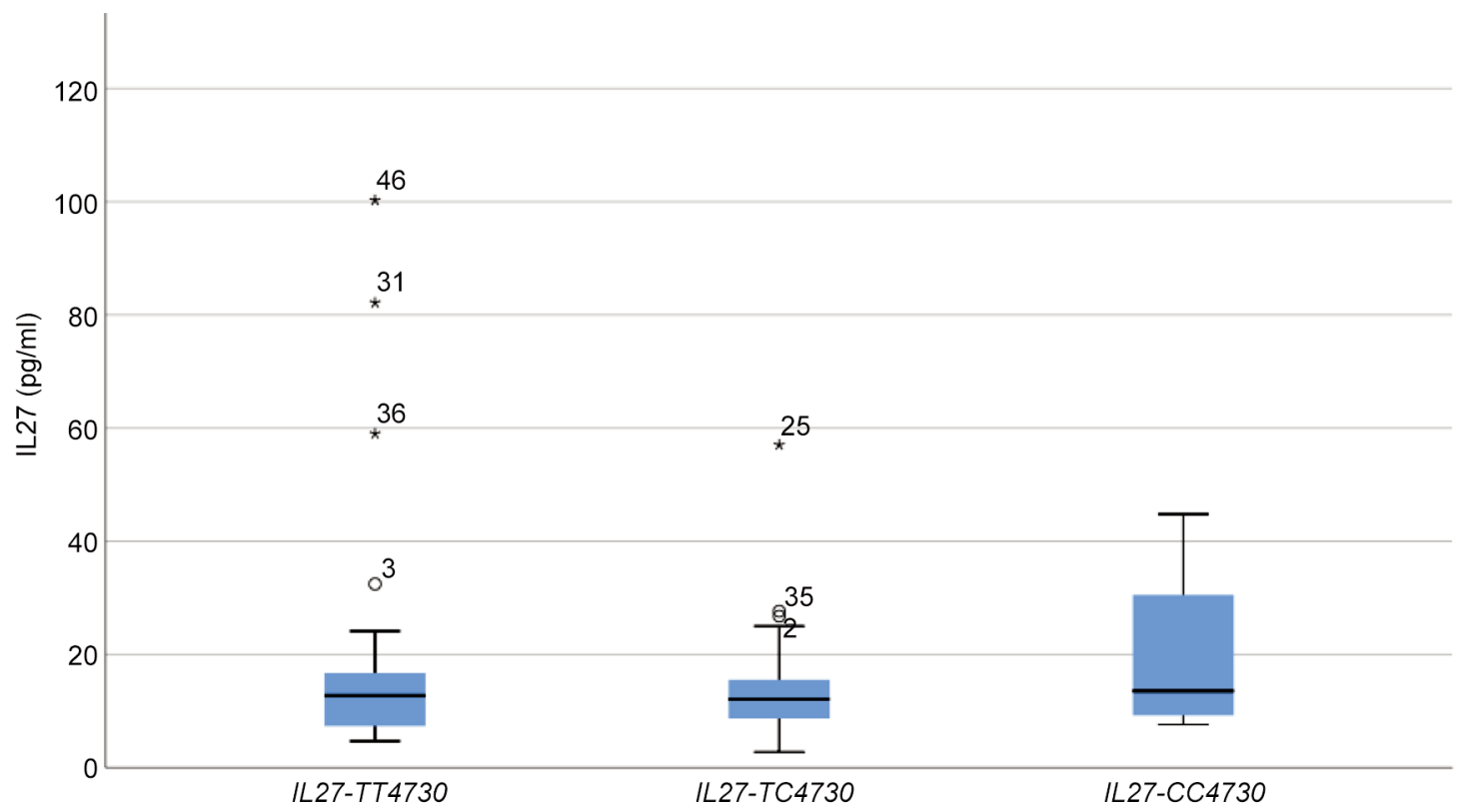

Figure 3. Serum levels of interleukin 27 (IL27) in patients with multiple sclerosis with different IL27-T4730C genotypes. The box defines the interquartile range (IQR), i.e., the distance between the third and the first quartile. The line inside the box is the median and the whiskers are the upper and lower limits bound by $1.5 \times I Q R$.

simultaneous presence of polymorphic alleles (for example the presence of both rs17855750 C and rs153109 G) modifying either the transcription initiation site or the structure of the transcription factor binding site, enhancing the production of IL17 and setting the scene for SLE development (33).

Interest was also manifested in the IL27 T4730C polymorphism in other autoimmune diseases, in an attempt to find a connection between the genetic background and disease onset or evolution. In autoimmune thyroid diseases, Graves' disease and Hashimoto's thyroiditis, no correlation was found of these diseases with this polymorphism (34). In RA, Paradowska-Gorycka et al. did not find significant differences in genotypic and allelic frequencies of the IL27 T4730C variant between patients with RA and controls, suggesting that this polymorphism is not associated with the susceptibility to RA in the investigated Polish population (35).

The differences between our findings and the previously reported results might be due to the different pathogenesis and molecular mechanisms involved in the occurrence of the diseases. Moreover, ethnicity, racial and age differences between the studied populations may have influenced our results.

To our knowledge, for Romania, this is the first study attempting to find an association between T4730C (rs 181206) polymorphism, serum IL27 level and susceptibility to MS.

The univariate logistic regression analysis showed that smoking, IL27 T4730C polymorphism and the presence of
C4730 allele represent risk factors for MS. The multivariate analysis confirmed that smoking and IL27 T4730C polymorphism represent independent risk factors for MS in this cohort of individuals. Other studies evaluating the risk factors for MS also demonstrated an association between smoking habit and the development of MS $(36,37)$.

In our MS group, we analyzed the potential association between IL27 T4730C polymorphism, age and laboratory. Parameters. We found no significant influence of IL27 T4730C genotype on the age at onset of the disease in the dominant or in the recessive model.

Si et al. examined the role of IL27 polymorphisms, including the $T 4730 \mathrm{C}$ polymorphism, in pediatric patients with Kawasaki disease, suggesting that the serum level of IL27 may not be directly associated with its polymorphisms, despite an elevated serum IL27 level in patients compared to controls (19). Vargas-Alarcón et al. (38) and Pang et al. (39) investigated this polymorphism in diseases other than autoimmune ones, in insulin resistance and in patients presenting HIV infection. Both studies found a reduced serum level of IL27 in patients with the variant compared to healthy individuals but no association was found between the genetic polymorphism, the expression of cytokines and these diseases.

Other studies, with different approaches, evaluated distinct facets of the immune involvement of IL27 in MS pathogenesis. A study conducted by Lalive et al. showed that patients with MS and active demyelination presented astrocytes producing IL27 in active plaques and higher 
cerebrospinal fluid levels of IL27 compared to controls (40).

The discovery of IL27 and the extensive evaluation of its roles and implications in autoimmune diseases led to the desire of using IL27 as a therapeutic tool, as suggested by Yoshida et al. (14), Hirahara et al. (41), Senecal et al. (14) and Zhu et al. (42).

We confirmed the level of IL27 to be lower in carriers of the IL27-T4730C polymorphism but no significant associations between genotypes (TC4730, CC4730) and serum IL27 level were found.

Despite revealing for the first time that $74730 \mathrm{C}$ gene polymorphism in IL27 is clearly related to the susceptibility to developing MS, our study has some limitations. One of the main limitations is the sample size, which may not be large enough to draw a definite conclusion about the relationship between this gene polymorphism and MS susceptibility. The second limitation is that one single gene polymorphism was tested among patients with MS and healthy individuals. The third limitation is related to the impossibility of evaluating the effect of $T 4730 \mathrm{C}$ polymorphism on treatment response because all the patients included in our study were evaluated prior to therapy initiation. In our study we did not take into account other known susceptibility loci for MS, as confounding factors. Other limitations of our study are the low analytical sensitivity in the determination of serum IL27 and lack of the evaluation of IL27 in cerebrospinal fluid. A larger cohort of patients is required in order to draw a more precise conclusion and extending the evaluation to other ethnic groups could be further explored.

Identifying patients with IL27 polymorphisms might improve the recognition of patients at risk for MS, in carriers of genetic susceptibility, opening new perspectives for prevention before an autoimmune status is established. Further studies are needed to determine how to manage the complex functions of IL27, challenging the therapeutic perspectives and in finding the right modality to use IL27 as a treatment to maintain the balance between autoimmune, infectious and neoplastic risk. It is clear that the treatment and the course of MS (relapse versus remission versus progression) influence the serum level of IL27. Extensive studies are required in order to elucidate the precise variation of IL27 in relation to the therapy used in MS and the stage of disease.

\section{Conclusion}

In conclusion, carriers of IL27 T4730C polymorphism (rs 181206) appear to have a higher risk of developing MS. The serum level of IL27 in patients without any treatment was significantly lower compared to controls. Our results add new insight into the genetic contribution of IL27 variation to MS susceptibility and support the crucial role of
IL27 in autoimmunity, but further investigations are still required to understand the context-dependent inflammatory activities of IL27.

\section{Conflicts of Interest}

The Authors declare no conflicts of interest.

\section{Authors' Contributions}

Conceptualization: I. S. Barac. and L.M Procopciuc.; methodology: L.M. Procopciuc, Decea Nicoleta.; software: Mădălina Vălean; validation: L.M. Procopciuc, Angela Cozma, M. F. Dafin; formal analysis: Mădălina Vălean; investigation: I. S. Barac, Vitalie Văcăraș; resources: I. S. Barac, Vitalie Văcăraș, M. F. Dafin; data curation: L.M Procopciuc, Mădălina Vălean ; writing-original draft preparation: I. S. Barac and L.M Procopciuc; writing-review and editing: I. S. Barac and L.M Procopciuc; visualization: Angela Cozma, M. F. Dafin; supervision: Vitalie Văcăraș, M. F. Dafin; project administration: L.M Procopciuc; funding acquisition: I. S. Barac. All Authors have read and agreed to the published version of the article.

\section{Acknowledgements}

The Authors are thankful to the participants and to Stefan Cristian Vesa for his contribution to the design of the article. This work was supported by a research grant from Iuliu Hațieganu University of Medicine and Pharmacy (project number: 1529/27 doctoral research grant).

\section{References}

1 Rostami A and Ciric B: Role of Th17 cells in the pathogenesis of CNS inflammatory demyelination. J Neurol Sci 333(1-2): 7687, 2013. PMID: 23578791. DOI: 10.1016/j.jns.2013.03.002

2 Tarlinton RE, Khaibullin T, Granatov E, Martynova E, Rizvanov $\mathrm{A}$ and Khaiboullina S: The interaction between viral and environmental risk factors in the pathogenesis of multiple sclerosis. Int J Mol Sci 20(2): 303, 2019. PMID: 30646507. DOI: $10.3390 /$ ijms20020303

3 Oksenberg JR and McCauley JL: Genetics of Multiple Sclerosis. In: Translational Neuroimmunology in Multiple Sclerosis. Elsevier, pp. 45-54, 2016.

4 Cho JH and Feldman M: Heterogeneity of autoimmune diseases: pathophysiologic insights from genetics and implications for new therapies. Nat Med 21(7): 730-738, 2015. PMID: 26121193. DOI: $10.1038 / \mathrm{nm} .3897$

5 Jabri B and Sollid LM: T cells in celiac disease. J Immunol 198(8): 3005-3014, 2017. PMID: 28373482. DOI: 10.4049/ jimmunol.1601693

6 Davidson A and Diamond B: General features of autoimmune disease. In: The Autoimmune Diseases. Elsevier, pp. 17-44, 2020.

7 Do J, Kim D, Kim S, Valentin-Torres A, Dvorina N, Jang E, Nagarajavel V, DeSilva TM, Li X, Ting AH, Vignali DAA, Stohlman SA, Baldwin WM 3rd and Min B: Treg-specific IL27R $\alpha$ deletion uncovers a key role for IL-27 in Treg function to control autoimmunity. Proc Natl Acad Sci U.S.A. 114(38): 1019010195, 2017. PMID: 28874534. DOI: 10.1073/pnas.1703100114 
8 Urazova OI, Churina EG, Hasanova RR, Novitskiy VV and Poletika VS: Association between polymorphisms of cytokine genes and secretion of IL-12p70, IL-18, and IL-27 by dendritic cells in patients with pulmonary tuberculosis. Tuberculosis (Edinb) 115: 56-62, 2019. PMID: 30948177. DOI: 10.1016/ j.tube.2019.02.003

9 Jankowski $\mathrm{M}$ and Wandtke $\mathrm{T}$ : Interleukin-27: Biological Properties and Clinical Application First Edition. Cham, Springer International Publishing, 2016.

10 Tait Wojno ED, Hunter CA and Stumhofer JS: The immunobiology of the interleukin-12 family: room for discovery. Immunity 50(4): 851-870, 2019. PMID: 30995503. DOI: 10.1016/j.immuni.2019.03.011

11 Bosmann M and Ward PA: Modulation of inflammation by interleukin-27. J Leukoc Biol 94(6): 1159-1165, 2013. PMID: 23904441. DOI: $10.1189 /$ jlb.0213107

12 Garces K, Carmy T, Illiano P, Brambilla R and Hackam AS: Increased neuroprotective microglia and photoreceptor survival in the retina from a peptide inhibitor of myeloid differentiation factor 88 (MyD88). J Mol Neurosci 70(6): 968980, 2020. PMID: 32072483. DOI: 10.1007/s12031-02001503-0

13 Tüzün E: Immunopathological factors associated with disability in multiple sclerosis. Noro Psikiyatr Ars 55(Suppl 1): S26-S30, 2018. PMID: 30692851. DOI: 10.29399/npa.23303

14 Sénécal V, Deblois G, Beauseigle D, Schneider R, Brandenburg J, Newcombe J, Moore CS, Prat A, Antel J and Arbour N: Production of IL-27 in multiple sclerosis lesions by astrocytes and myeloid cells: Modulation of local immune responses. Glia 64(4): 553-569, 2016. PMID: 26649511. DOI: 10.1002/ glia.22948

15 Yamamoto-Furusho JK, Posadas-Sánchez R, Alvarez-León E and Vargas-Alarcón G: Protective role of Interleukin 27 (IL-27) gene polymorphisms in patients with ulcerative colitis. Immunol Lett 172: 79-83, 2016. PMID: 26905929. DOI: 10.1016/ j.imlet.2016.02.010

16 Anaraki mohammadi S, Mansouri R, Shahi A, Akhlaghi M, Dashti N, Aslani S, Mansouri M, Poursani S and Mahmoudi M: IL27 gene single nucleotide polymorphisms confer susceptibility to rheumatoid arthritis in Iranian population. Meta Gene 18: 149-152, 2018. DOI: 10.1016/j.mgene.2018.09.002

17 Chae SC, Li CS, Kim KM, Yang JY, Zhang Q, Lee YC, Yang YS and Chung HT: Identification of polymorphisms in human interleukin-27 and their association with asthma in a Korean population. J Hum Genet 52(4): 355-361, 2007. PMID: 17318299. DOI: $10.1007 / \mathrm{s} 10038-007-0123-8$

18 rs181206 (SNP) - Citations - Homo sapiens - GRCh37 Archive browser 100. Available at: http://grch37.ensembl.org/ Homo_sapiens/Variation/Citations?db=core;g=ENSG000001972 72;r=16:28510683-28518155;t=ENST00000356897; $=\mathrm{vs} 181206$; $\mathrm{vdb}=$ variation; $\mathrm{vf}=309953932$ [Last accessed on August 3, 2020]

19 Si F, Wu Y, Wang X, Gao F, Yang D, Liu R and Yi Q: The relationship between Interleukin-27 gene polymorphisms and Kawasaki disease in a population of Chinese children. Cardiol Young 28(9): 1123-1128, 2018. PMID: 29973303. DOI: $10.1017 / \mathrm{S} 1047951118000914$

20 Sureau A, Gattoni R, Dooghe Y, Stévenin J and Soret J: SC35 autoregulates its expression by promoting splicing events that destabilize its mRNAs. EMBO J 20(7): 1785-1796, 2001. PMID: 11285241. DOI: 10.1093/emboj/20.7.1785
21 Posadas-Sánchez R, Pérez-Hernández N, Rodríguez-Pérez JM, Coral-Vázquez RM, Roque-Ramírez B, Llorente L, Lima G, Flores-Dominguez C, Villarreal-Molina T, Posadas-Romero C and Vargas-Alarcón G: Interleukin-27 polymorphisms are associated with premature coronary artery disease and metabolic parameters in the Mexican population: the genetics of atherosclerotic disease (GEA) Mexican study. Oncotarget 8(38): 64459-64470, 2017. PMID: 28969085. DOI: 10.18632/oncotarget.16223

22 Thompson AJ, Banwell BL, Barkhof F, Carroll WM, Coetzee T, Comi G, Correale J, Fazekas F, Filippi M, Freedman MS, Fujihara K, Galetta SL, Hartung HP, Kappos L, Lublin FD, Marrie RA, Miller AE, Miller DH, Montalban X, Mowry EM, Sorensen PS, Tintoré M, Traboulsee AL, Trojano M, Uitdehaag BMJ, Vukusic S, Waubant E, Weinshenker BG, Reingold SC and Cohen JA: Diagnosis of multiple sclerosis: 2017 revisions of the McDonald criteria. Lancet Neurol 17(2): 162-173, 2018. PMID: 29275977. DOI: 10.1016/S1474-4422(17)30470-2

23 Faul F, Erdfelder E, Lang AG and Buchner A: G*Power 3: a flexible statistical power analysis program for the social, behavioral, and biomedical sciences. Behav Res Methods 39(2): 175-191, 2007. PMID: 17695343. DOI: 10.3758/bf03193146

24 Moudgil KD and Choubey D: Cytokines in autoimmunity: role in induction, regulation, and treatment. J Interferon Cytokine Res 31(10): 695-703, 2011. PMID: 21942420. DOI: 10.1089/ jir.2011.0065

25 Yoshida $\mathrm{H}$ and Hunter CA: The immunobiology of interleukin27. Annu Rev Immunol 33: 417-443, 2015. PMID: 25861977. DOI: 10.1146/annurev-immunol-032414-112134

26 Babaloo Z, Yeganeh RK, Farhoodi M, Baradaran B, Bonyadi M and Aghebati L: Increased IL-17A but decreased IL-27 serum levels in patients with multiple sclerosis. Iran J Immunol 10(1): 47-54, 2013. PMID: 23502338. DOI: IJIv10i1A6

27 Tang SC, Fan XH, Pan QM, Sun QS and Liu Y: Decreased expression of IL-27 and its correlation with Th1 and Th17 cells in progressive multiple sclerosis. J Neurol Sci 348(1-2): 174180, 2015. PMID: 25498842. DOI: 10.1016/j.jns.2014.11.035

28 Hasheminia SJ, Tolouei S, Zarkesh-Esfahani SH, Shaygannejad V, Shirzad HA, Torabi R and Hashem Zadeh Chaloshtory M: Cytokines gene expression in newly diagnosed multiple sclerosis patients. Iran J Allergy Asthma Immunol 14(2): 208-216, 2015. PMID: 25780887.

29 Naderi S, Hejazi Z, Shajarian M, Alsahebfosoul F, Etemadifar $\mathrm{M}$ and Sedaghat N: IL-27 plasma level in relapsing remitting multiple sclerosis subjects: The double-faced cytokine. J Immunoassay Immunochem 37(6): 659-670, 2016. PMID: 27249307. DOI: 10.1080/15321819.2016.1195746

30 Romme Christensen J, Börnsen L, Hesse D, Krakauer M, Sørensen PS, Søndergaard HB and Sellebjerg F: Cellular sources of dysregulated cytokines in relapsing-remitting multiple sclerosis. J Neuroinflammation 9: 215, 2012. PMID: 22978757. DOI: $10.1186 / 1742-2094-9-215$

31 Li TT, Zhang T, Chen GM, Zhu QQ, Tao JH, Pan HF and Ye DQ: Low level of serum interleukin 27 in patients with systemic lupus erythematosus. J Investig Med 58(5): 737-739, 2010. PMID: 20216231. DOI: 10.231/JIM.0b013e3181d88f7b

32 Duarte AL, Dantas AT, de Ataíde Mariz H, dos Santos FA, da Silva JC, da Rocha LF Jr, Galdino SL and Galdino da Rocha Pitta M: Decreased serum interleukin 27 in Brazilian systemic lupus erythematosus patients. Mol Biol Rep 40(8): 4889-4892, 2013. PMID: 23645091. DOI: 10.1007/s11033-013-2588-1 
33 Paradowska-Gorycka A, Sowinska A, Stypinska B, Grobelna MK, Walczyk M, Olesinska M, Piotrowski P and Jagodzinski PP: Genetic variants in IL-12B and IL-27 in the Polish patients with systemic lupus erythematosus. Scand J Immunol 84(1): 4960, 2016. PMID: 27059274. DOI: 10.1111/sji.12439

34 He W, Wang B, Mu K, Zhang J, Yang Y, Yao W, Li S and Zhang JA: Association of single-nucleotide polymorphisms in the IL27 gene with autoimmune thyroid diseases. Endocr Connect 8(3): 173-181, 2019. PMID: 30694795. DOI: 10.1530/EC-18-0370

35 Paradowska-Gorycka A, Raszkiewicz B, Jurkowska M, FelisGiemza A, Romanowska-Prochnicka K, Mańczak M and Olesinska M: Association of single nucleotide polymorphisms in the IL27 gene with rheumatoid arthritis. Scand J Immunol 80(4): 298-305, 2014. PMID: 25041531. DOI: 10.1111/sji.12209

36 Ammitzbøll C, Börnsen L, Petersen ER, Oturai AB, Søndergaard HB, Grandjean P and Sellebjerg F: Perfluorinated substances, risk factors for multiple sclerosis and cellular immune activation. J Neuroimmunol 330: 90-95, 2019. PMID: 30852181. DOI: 10.1016/j.jneuroim.2019.03.002

37 Alrouji M, Manouchehrinia A, Gran B and Constantinescu CS: Effects of cigarette smoke on immunity, neuroinflammation and multiple sclerosis. J Neuroimmunol 329: 24-34, 2019. PMID: 30361070. DOI: 10.1016/j.jneuroim.2018.10.004

38 Vargas-Alarcón G, Pérez-Hernández N, Rodríguez-Pérez JM, Fragoso JM, Posadas-Romero C, López-Bautista F, VázquezVázquez $\mathrm{C}$ and Posadas-Sánchez R: Interleukin 27 polymorphisms, their association with insulin resistance and their contribution to subclinical atherosclerosis. The GEA Mexican study. Cytokine 114: 32-37, 2019. PMID: 30594065. DOI: $10.1016 /$ j.cyto.2018.11.028
39 Pang XX, Luo SD, Zhang T, Shi F, Wang CF, Chen XH, Wei YX, Qin L, Wei JX, Luo XQ and Wang JL: Association of interleukin-27 gene polymorphisms with susceptibility to HIV infection and disease progression. J Cell Mol Med 23(4): 24102418, 2019. PMID: 30632263. DOI: 10.1111/jcmm.14067

40 Lalive PH, Kreutzfeldt M, Devergne O, Metz I, Bruck W, Merkler D and Pot C: Increased interleukin-27 cytokine expression in the central nervous system of multiple sclerosis patients. J Neuroinflammation 14(1): 144, 2017. PMID: 28738904. DOI: 10.1186/s12974-017-0919-1

41 Hirahara K, Ghoreschi K, Yang XP, Takahashi H, Laurence A, Vahedi G, Sciumè G, Hall AO, Dupont CD, Francisco LM, Chen Q, Tanaka M, Kanno Y, Sun HW, Sharpe AH, Hunter CA and O'Shea JJ: Interleukin-27 priming of T cells controls IL-17 production in trans via induction of the ligand PD-L1. Immunity 36(6): 1017-1030, 2012. PMID: 22726954. DOI: 10.1016/ j.immuni.2012.03.024

42 Zhu J, Liu JQ, Liu Z, Wu L, Shi M, Zhang J, Davis JP and Bai XF: Interleukin-27 gene therapy prevents the development of autoimmune encephalomyelitis but fails to attenuate established inflammation due to the expansion of $\mathrm{CD} 11 \mathrm{~b}^{+} \mathrm{Gr}-1^{+}$myeloid cells. Front Immunol 9: 873, 2018. PMID: 29740452. DOI: 10.3389/fimmu.2018.00873
Received May 12, 2021

Revised May 31, 2021

Accepted June 4, 2021 